\title{
Anticancer Activity of Camel Milk via Induction of Autophagic Death in Human Colorectal and Breast Cancer Cells
}

\author{
Roopesh Krishnankutty ${ }^{1 *}$, Ahmad Iskandarani ${ }^{1}$, Lubna Therachiyil ${ }^{1}$, Shahab \\ Uddin', Fouad Azizi', Michael Kulinski', Ajaz Ahmad Bhat ${ }^{1,2}$, Ramzi M \\ Mohammad $^{1,3}$
}

\begin{abstract}
Background/ Objective: Camel milk is traditionally known for its human health benefits and believed to be a remedy for various human ailments including cancer. The study was aimed to evaluate the inhibitory effects of commercially available camel milk on cancer cells and its underlying mechanism(s). Materials and Methods: Two cell lines: colorectal cancer HCT 116 and breast cancer MCF-7 were cultured with different doses of camel milk. The effects of camel milk on cell death were determined by MTT assay, viability by trypan blue exclusion assay and migration by in vitro scratch assay. The mechanism was elucidated by western blotting and confocal microscopy was used to confirm autophagy. Results: Camel milk significantly reduced proliferation, viability as well as migration of both the cells. The accumulation of LC3-II protein along with reduction in expression of p62 and Atg 5-12, the autophagy proteins implied induction of autophagy. The (GFP)-LC3 puncta detected by confocal microscopy confirmed the autophagosome formation in response to camel milk treatment. Conclusion: Camel milk exerted antiproliferative effects on human colorectal HCT 116 and breast MCF-7 cancer cells by inducing autophagy.
\end{abstract}

Keywords: Colorectal cancer- breast cancer- camel milk- autophagy

Asian Pac J Cancer Prev, 19 (12), 3501-3509

\section{Introduction}

Cancer forms one of the leading causes of millions of deaths worldwide. An increasing incidence in the prevalence of this fatal disease is being observed in the Middle East region, with the breast cancer (Al-Kuraya et al., 2005) and colon cancer (Arafa and Farhat, 2015) ranking high, especially within the State of Qatar (Rasul et al., 2001; Bener et al., 2008; Bener et al., 2010; Bener et al., 2012). Among Arab women, breast cancer is ranked first among all cancers and has the highest rate of morbidity and mortality among women (Bazarbashi et al., 2017). Breast cancers originating from this ethnic population are found to have an advanced stage, high grade and tend to affect a younger population as compared to the west (Al Tamimi et al., 2010). In the case of colon cancer though the incidence of occurrence has decreased in the west, it is observed to be increasing in the gulf region and forms the third most common cancer in Qatar (Rasul et al., 2001; Arafa and Farhat, 2015). The standard therapies for managing this disease includes surgery, chemotherapy, radiotherapy and immunotherapy (Kittaneh et al., 2013). Although these treatment strategies had significantly progressed through the invention of novel therapeutic targets/drugs, the management of this disease is still a major challenge, as there are no medical modalities available until now that can selectively target and kill cancer cells. For example, chemotherapy the primary treatment mode for many cancer types is being characterized by its toxicity on normal cells resulting in potential lethal side effects sometimes leading to life-long morbidities (Rossi et al., 2008). These drawbacks intensify the imperative need for devising alternative treatment/ management strategies with minimal side effects.

Naturally occurring bioactive compounds have contributed effectively into cancer therapeutics paving way for better disease management, with their source of origin being either plants or animals (Kommanee et al., 2012; Mothana et al., 2012). Dietary constituents in the form of functional food has attracted much attention due to their ability in providing multitude of human health benefits with less or no toxicity and emerged as a novel approach to control cancer (Kontou et al., 2011). Camel milk is such a dietary food with profound nutraceutical value (Alebie et al., 2017). It forms a high nutritional source with low cholesterol, low sugar, high minerals

${ }^{1}$ Translational Research Institute, Academic Health System, Hamad Medical Corporation, ${ }^{2}$ Division of Translational Medicine, Research Branch, Sidra Medicine, Doha, State of Qatar, ${ }^{3}$ Department of Oncology, Barbara Ann Karmanos Cancer Institute, Wayne State University School of Medicine, Detroit, MI, USA. *For Correspondence: rkrishnankutty@hamad.qa 
(sodium, potassium, iron, copper, zinc and magnesium), high vitamins (vitamin $\mathrm{C}, \mathrm{B}_{2}, \mathrm{~A}$ and $\mathrm{E}$ ) and high concentrations of insulin (Haddadin et al., 2008; Alhaider et al., 2014) compared to the ruminant milk.

Camel milk and its products have been reported to possess various human health benefits and used as a medicine to treat human diseases such as hepatitis, spleen problems (Korish and Arafah, 2013), diarrhea (Yagil, 2013), psoriasis (Wernery, 2006) etc. Camel milk has been reported to be very effective against bacteria: Escherichia coli, Staphylococcus aureus, Salmonella typhimurium and also rotavirus (Harrison et al., 2003). Camel milk is known to exhibit significant antioxidant effects (Korish and Arafah, 2013) as well as possess protective proteins which includes lysozyme, lactoperoxidase and lactoferrin (Agrawal et al., 2009; Shamsia, 2009).

It is being traditionally believed that drinking camel milk would help to fight against various human ailments including cancers, however, this proclaimed health benefits of the camel milk is not well recognized due to limited scientific study reports. A few of the in vitro studies have reported the inhibitory effects of camel milk on cancer cells exerted through the mechanism of apoptosis (Korashy et al., 2012b; Hasson et al., 2015) and antioxidant activities (Habib et al., 2013). Some of the in vivo studies have also shown the potent inhibitory effects of camel milk on pro-inflammatory, pro-angiogenic and pro-fibrogenic cytokines (Alhaider et al., 2014) as well as the ability of camel milk to modulate the expression of known cancer-activating gene and cancer-protective genes at the transcriptional and posttranscriptional levels (Korashy et al., 2012a). However, no studies exist so far, testifying the effect of a commercially available camel milk on cancer cells.

The objective of the current study was to evaluate the inhibitory effects of camel milk on proliferation, viability and migration of human colorectal HCT 116 and breast MCF-7 cancer cells as well as explore the underlying molecular mechanism(s). The assays such as trypan blue exclusion and MTT were used to determine the effect of camel milk on cancer cells viability as well as proliferation. An in vitro scratch assay was used to check the effect of camel milk on migration of cancer cells. We have also attempted to elucidate the mechanism behind the inhibitory effects of camel milk on cancer cells by identifying the various protein markers involved in the cell death pathway.

\section{Materials and Methods}

\section{Reagents}

Dulbecco's Modified Eagle's Medium (DMEM), Radioimmunoprecipitation assay (RIPA) buffer, protease inhibitor cocktail, 3-(4,5-dimethylthia- zol-2-yl)-2,5diphenyltetrazolium bromide (MTT), fetal bovine serum (FBS), trypsin, phosphate buffered saline (PBS) were purchased from Sigma-Aldrich Chemical Co. (St. Louis, MO, USA). All the antibodies, primary and secondary were purchased from Cell Signaling Technology (Danvers, MA, USA). Lipofectamine 2000 transfection reagent was purchased from Invitrogen (Carlsbad, USA). Camel milk and bovine milk were purchased locally from the supermarket in the State of Qatar.

\section{Cell culture and treatment}

Colorectal cancer HCT 116 and breast cancer MCF-7 cells were obtained from the American Type Culture Collection (ATCC, Manassas, VA, USA). Cells were maintained in DMEM (Gibco), supplemented with 10\% fetal bovine serum (FBS), 1\% penicillin-streptomycin $(100 \mathrm{U} / \mathrm{ml})$ and $2 \mathrm{mmol} / \mathrm{L}$ glutamine (Hyclone Logan) at $37^{\circ} \mathrm{C}$ in a humidified atmosphere of $5 \% \mathrm{CO}_{2}$. Cells were cultured in serum-free medium before treatment with different doses of camel milk.

\section{Cell viability and proliferation assay}

Cells $\left(5.0 \times 10^{5}\right.$ cells/well) were cultured in 6-well plates in the absence and presence of camel milk at different doses $(25,50,100,150$ and $250 \mu \mathrm{L} / \mathrm{mL})$ for 24, 48 and $72 \mathrm{~h}$ while, with bovine milk at doses: 100 and $250 \mu \mathrm{L} / \mathrm{mL}$ for $48 \mathrm{~h}$. Cells were trypsinized, washed with phosphate buffered saline (PBS), mixed with trypan blue and counted on TC $($ automated cell counter (Bio-Rad) for viability. Cell proliferation was determined by 3-(4,5-dimethylthiazol-2-yl)-2,5-diphenyltetrazolium (MTT) assay. (Mosmann, 1983). The cells were seeded into 96 well plates and maintained at $37^{\circ} \mathrm{C}$ in a humidified atmosphere of $5 \% \mathrm{CO}_{2}$ for $24 \mathrm{~h}$. The cells were then treated with varying concentrations ( 25 to $250 \mu \mathrm{L} / \mathrm{mL}$ ) of camel milk and incubated for 24,48 and $72 \mathrm{~h}$. The media were then removed and $100 \mu \mathrm{L}$ of serum-free media with MTT (1.2 mM) was added. The plates were further incubated at $37^{\circ} \mathrm{C}, 5 \% \mathrm{CO}_{2}$ for $4 \mathrm{~h}$. The reaction was stopped by decanting the media by inverting the plates and the formazan crystals were dissolved in $200 \mu \mathrm{L}$ of $10 \%$ sodium dodecyl sulphate (SDS) prepared in deionized water by incubating at $37^{\circ} \mathrm{C}$ for overnight. The color intensity was measured at $630 \mathrm{~nm}$ using microplate reader (Tecan, BioTek Instruments Inc. Winooski, VT, USA). Six replicate measurements with three independent experiments were carried out. The cell proliferation was determined as percentage in relative to the control (untreated) wells designated as having 100\% proliferating cells.

\section{In vitro wound healing assay}

The effect of camel milk on cell migration was determined by in vitro scratch assay for wound healing (Liang et al., 2007). Cells were cultured in 6-well plates $\left(5.0 \times 10^{4}\right.$ cells/well) yielding confluent monolayer. Wounds were created by scratching monolayer using a sterile $200 \mu \mathrm{L}$ pipet tip. After incubation in the absence and presence of camel milk, plates were photographed under a Nikon DMCI microscope (Nikon, Tokyo, Japan). The images were further analyzed quantitatively using Image J (http://rsb.info.nih.gov/ij/) software.

\section{Western blot analysis}

Cells were treated with different doses of camel milk and were lysed in cold RIPA buffer [1\% (w/v) NP40, 1\% (w/v) sodium deoxycholate, $0.1 \%$ (w/v) SDS, 0z.15 M $\mathrm{NaCl}, 0.01 \mathrm{M}$ sodium phosphate buffer, $\mathrm{pH}$ 7.2, $2 \mathrm{mM}$ 
EDTA, and $50 \mathrm{mM}$ phosphatase inhibitor cocktail]. The cell lysates were centrifuged at $14,000 \mathrm{x}$ g for $10 \mathrm{~min}$ at $4 \mathrm{oC}$ and the supernatant (total protein) obtained were quantified by bicinchoninic acid (BCA) protein assay (Thermo Scientific Pierce kit) using bovine serum albumin as standard. Equal amounts of protein were separated on a $12 \%$ SDS gel by electrophoresis $(100 \mathrm{~V}, 2 \mathrm{~h})$ and were transferred to polyvinylidene difluoride (PVDF) membrane. Membranes were probed with primary rabbit antibodies against poly (ADP-ribose) polymerase (PARP), B-cell lymphoma 2 (Bcl-2), microtubule associated protein 1 light chain 3 (LC3), sequestosome 1 (SQSTM1 or p62), Autophagy (Atg5-12) and glyceraldehyde-3-phosphate dehydrogenase (GAPDH) and the bound antibodies detected with horseradish peroxidase-conjugated anti-rabbit Ig antibody using enhanced chemiluminescence system (BioRad Laboratories, Hercules, CA, USA). The band intensities were quantified using the software Image $\mathrm{J}$ and normalized against GAPDH.

\section{Green fluorescent protein (GFP)-LC3 detection of autophagosomes}

The HCT 116 and MCF-7 cells were transfected with pEGFP-LC3 plasmids using lipofectamine 2000 (Invitrogen) according to the manufacture's protocol. At $24 \mathrm{~h}$ of transfection, the cells were treated with or without camel milk $(100 \mu \mathrm{L} / \mathrm{mL})$ and incubated further for $24 \mathrm{~h}$ $\left(37^{\circ} \mathrm{C}, 5 \% \mathrm{CO}_{2}\right)$. The fluorescence of GFP-LC3-labeled vacuoles (autophagosomes) visualized as GFP-LC3 puncta was detected using confocal microscopy (A1Rsi Nikon eclipse Ti confocal microscope, 60x magnification).

\section{Statistical analysis}

All the experiments were performed in triplicates unless otherwise mentioned and independently three times to ensure reproducibility. The data are represented as mean \pm standard error of mean (SEM). The differences between the groups were analyzed using paired Student's t-test and difference with $\mathrm{p}<0.05$ was considered statistically significant.

\section{Results}

Camel milk exerts cytotoxicity to cancer cells

Camel milk was found to exhibit a time and dose-dependent cytotoxicity effects on both the cell lines tested (Figure 1a, b). Camel milk exerted significant cytotoxicity at higher concentrations (100 and $250 \mu \mathrm{L} /$ $\mathrm{mL}$ ) after $48 \mathrm{~h}$ in both the cell types as evident from the decrease in total percent cell viability compared to the control (untreated). In contrast, treatment of cells with bovine milk at higher concentrations $(250 \mu \mathrm{L} / \mathrm{mL})$ for 48 $\mathrm{h}$ did not show any toxicity on both the cell lines (Figure 1c, d). Similarly, camel milk treatment showed a time and dose-dependent decrease in cell proliferation (Figure $2 \mathrm{a}, \mathrm{b})$. In both the cell types tested, reduction in cell proliferation was observed at higher doses (100 and 250 $\mu \mathrm{L} / \mathrm{mL}$ ) after $48 \mathrm{~h}$. In fact, the proliferation of HCT 116 and MCF-7 cells decreased by 55 and $45 \%$ respectively, at $72 \mathrm{~h}$ after treatment. The half maximal inhibitory constant $\left(\mathrm{IC}_{50}\right)$ of camel milk was determined to be 31 and $51 \mu \mathrm{L} /$
mL for HCT 116 and MCF-7 cells respectively.

Camel milk reduces migration of cancer cells

Cell migration is a property of cancer cells that contributes to its potential to invade into other tissues or organs that can result in a condition of metastasis. A dose-dependent reduction in wound healing was observed in both the cell types treated with camel milk compared to their respective (untreated) controls (Figure 3a, c). A significant reduction in wound healing was achieved with $5 \%$ of wound closure in case of HCT 116 cells and $4 \%$ in the case of MCF-7 cells treated at the highest dose (Figure 3b, d).

\section{Camel milk did not trigger apoptosis in cancer cells}

To assess the mechanism behind the cytotoxicity effects exerted by the camel milk; the HCT 116 and MCF-7 cells were cultured in the absence or presence of camel milk. The protein lysates were immuno-blotted against the apoptotic protein marker: poly (ADP-ribose) polymerase (PARP). No PARP cleavage was detected in both the cell lines treated with camel milk (Figure 4a, e) indicating that the treatment did not trigger apoptosis. During apoptosis, the full length PARP protein $(116 \mathrm{kD})$ is cleaved by caspases into $89 \mathrm{kD}$ fragment which inactivates the enzyme thereby preventing its catalytic action against DNA damage repair (D'Amours et al., 2001). To further corroborate this finding, the protein extracts were tested for $\mathrm{Bcl}-2$ protein expression. $\mathrm{Bcl}-2$ is a known anti-apoptotic protein, implicating that $\mathrm{Bcl}-2$ protein will not favor apoptotic pathway mediated cell death (Brunelle and Letai, 2009). Bcl-2 family members play a significant and pivotal role in regulating apoptosis by maintaining a balance between anti-apoptotic molecules such as Bcl-2 and pro-apoptotic molecule Bax. Slight imbalance or disturbance in their levels leads to induction or inhibition of cell death (Martinou and Youle, 2011). Western blot analysis detected $\mathrm{Bcl}-2$ protein with no altered expression in control vs. treated (Figure 4a, e). The cell lysates were also immuno-blotted against caspase- 3 antibody and no cleaved caspase- 3 were detected (data not shown). Caspases are hallmark of apoptosis that propagates the death signal by activation of caspase- 3 that leads the activation and cleavage of PARP. Activation and cleavage of PARP in turn causes DNA fragmentation and cell death (Hussain et al., 2011). Taken together, these data indicated that growth inhibitory effects exerted by camel milk on these cells were not via apoptosis.

Camel milk treatment induced autophagy in cancer cells

The HCT 116 and MCF-7 cells cultured in the presence of camel milk were observed to exhibit significant morphological changes characterized mainly by lose of cell membrane integrity along with extensive vacuolization (Figure 5a, b). The LC3 (microtubule-associated protein1 light chain 3) protein is a known marker of autophagy. Studies have indicated that the lipidated form of LC3 transforming from LC3-I to LC3-II isomer can be correlated with the formation of autophagosomes and hence, LC3-II/LC3-I ratio forms a readout for the degree of autophagy (Tanida et al., 2004). A dose-dependent 

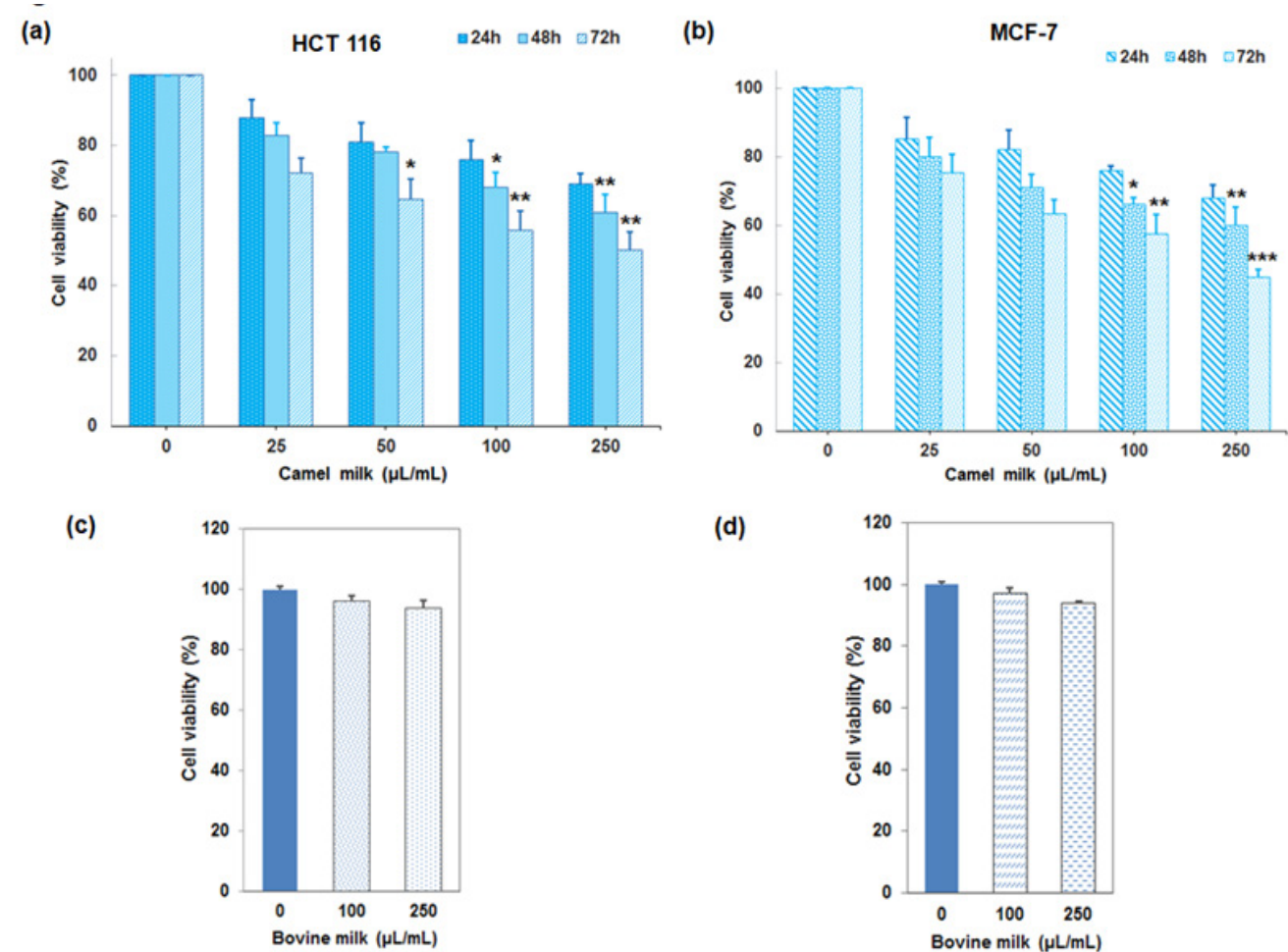

Figure 1. Effect of Camel Milk and Bovine Milk on Cell Viability. (a, b) HCT 116 and MCF-7 cells were seeded and after $2 \mathrm{~h}$ incubated with varying concentration of camel milk and the number of viable cells were counted after 24,48 and $72 \mathrm{~h}$ using trypan blue exclusion assay. Values represent percentage of the control $(0 \mu \mathrm{L} / \mathrm{mL})$ and are shown as mean \pm SEM $(\mathrm{n}=3), * p<0.03, * * p<0.003$. (c, d) HCT 116 and MCF-7 cells were seeded and after 24h were incubated with 100 and $250 \mu \mathrm{L} / \mathrm{mL}$ of bovine milk and the viable cell count was made after $48 \mathrm{~h}$ using trypan blue.

increase in the conversion of LC3-I to LC3-II was observed in both the cell lines cultured in the presence of camel milk (Figure 4b, f) with approximately 5-fold increase in the LC3-II/LC-I ratio as signified from the quantified values (histograms).

To further confirm the induction of autophagy by camel milk, the protein expression profile of autophagy markers such as p62 and Atg5-12 were tested. A significant ( 3 -fold) decrease (dose-dependent) of p62 protein expression was observed in both the cell lines treated with camel milk (Figure 4c, g) which implied the stimulation of autophagy. The protein Atg5 (autophagy protein 5) complexes with Atg12 (autophagy protein 12) and forms an essential component of autophagy which catalyzes the elongation of vesicular membrane leading to autophagosome formation. A concomitant dose-dependent decrease in the expression of Atg5-12 protein was observed in both the cell lines treated with camel milk (Figure 4d, h) which further confirms the elongation process of double vesicle membrane forming nascent autophagosomes. (a)

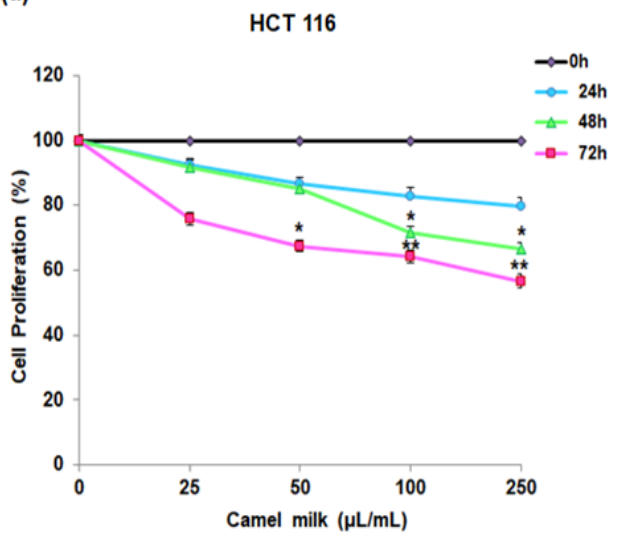

(b)

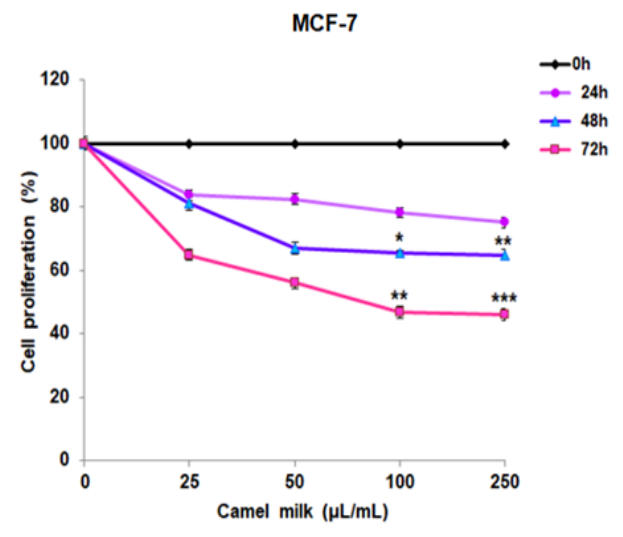

Figure 2. Effect of camel milk on cell proliferation. (a, b) HCT 116 and MCF-7 cells were seeded and incubated with various concentration of camel milk for 24,48 and $72 \mathrm{~h}$, thereafter cell proliferation was assessed using MTT assay. Values are presented as percentage of the control $(0 \mu \mathrm{L} / \mathrm{mL})$ and are shown as mean $\pm \operatorname{SEM}(\mathrm{n}=3), * p<0.03, * * p$ $<0.01, * * * p<0.001$. 
(a)

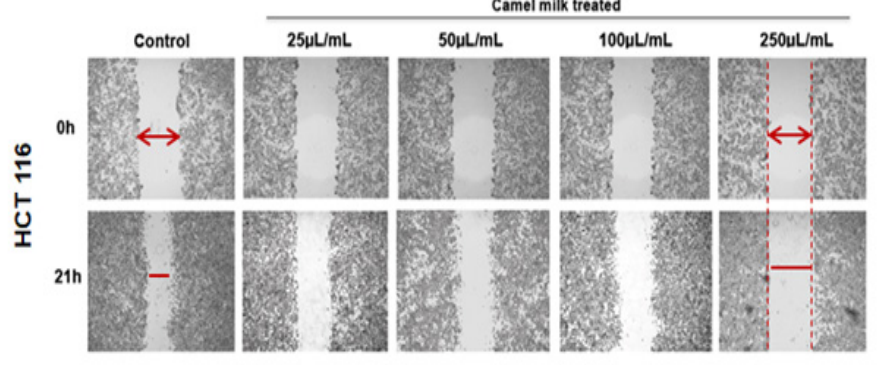

(c)

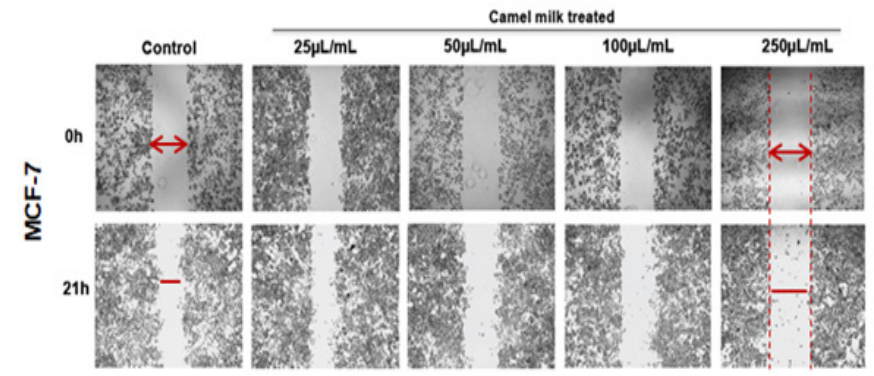

(b)

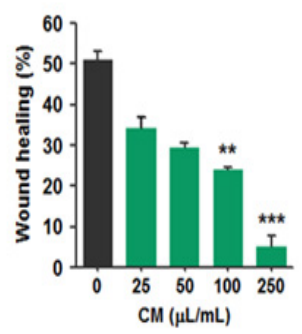

(d)

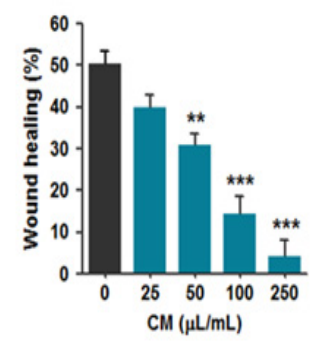

Figure 3. Effect of Camel Milk on Cell Migration, in vitro Scratch Wound Healing Assay. (a, c) HCT 116 and MCF-7 cells were grown in DMEM media to confluence, wounded $(\mathrm{t}=0 \mathrm{~h})$ by using a sterile pipette tip and then treated with various concentration of camel milk. After $21 \mathrm{~h}$, the migration of cells into the wound surface were captured under the microscope (magnification, 40x). Scale bar: $200 \mu \mathrm{m}$. (b, d): Percentage of wound healing relative to the distance measured in (a) and (c) quantified using Image J. Values are represented as mean \pm SEM, $* * p<0.02, * * * p<0.001$. Data are representative of triplicate experiments.
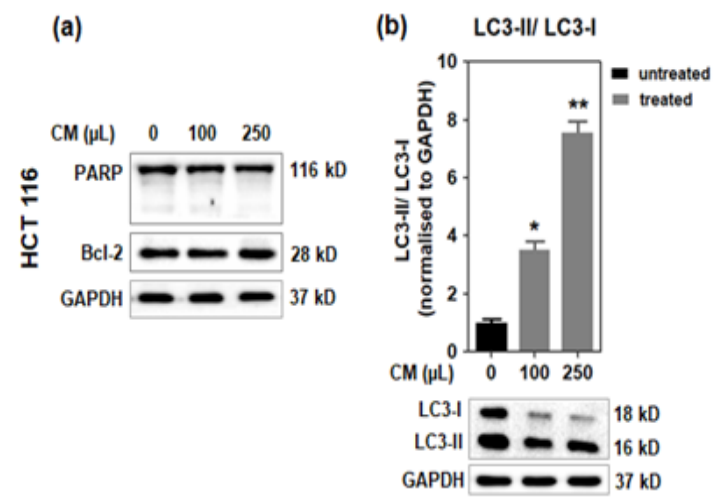

(e)

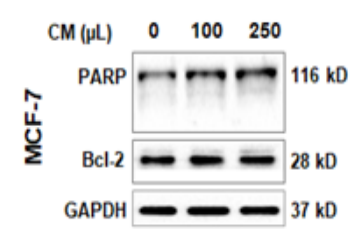

(f)

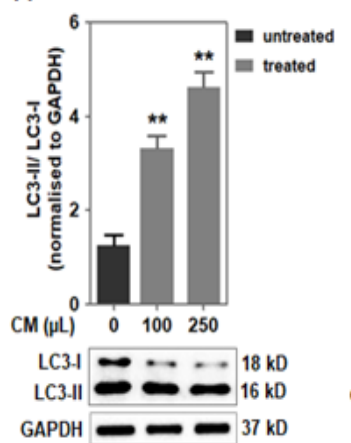

(c)

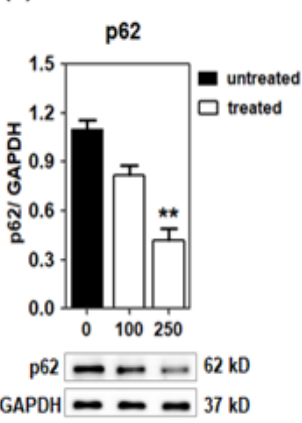

(g)

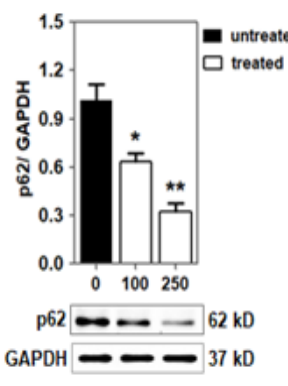

(d)

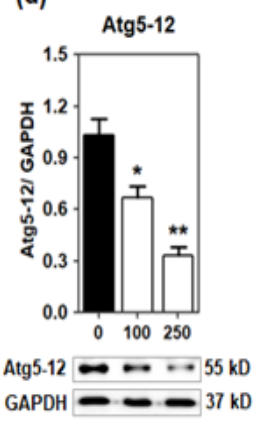

(h)

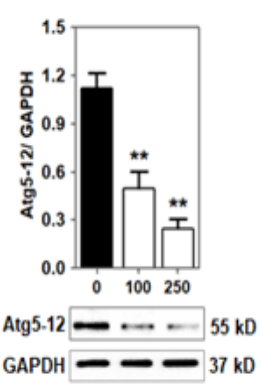

Figure 4. Effect of camel milk on apoptotic and autophagy markers. (a, e): HCT 116 and MCF-7 cells were treated with 100 and $250 \mu \mathrm{L} / \mathrm{mL}$ of camel milk for $48 \mathrm{~h}$. The expression of PARP and Bcl-2 proteins in the cell lysates were analysed by western blotting. HCT 116: (b-d) and MCF-7: (f-h); the protein lysates were tested for the expression of LC3, p62 and Atg5-12 proteins by western blotting analysis. GAPDH served as the loading control. The band intensities were quantified using Image $J$ and normalised against GAPDH. The data are from triplicate experiments and presented as mean \pm SEM, ${ }^{*} p<0.03, * * p<0.01$. 
(a)

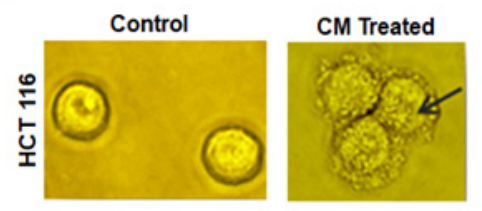

(b)

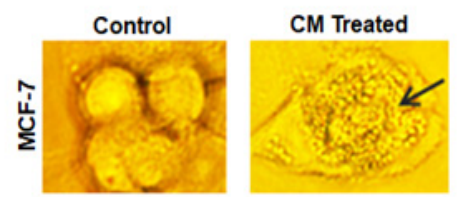

(d)

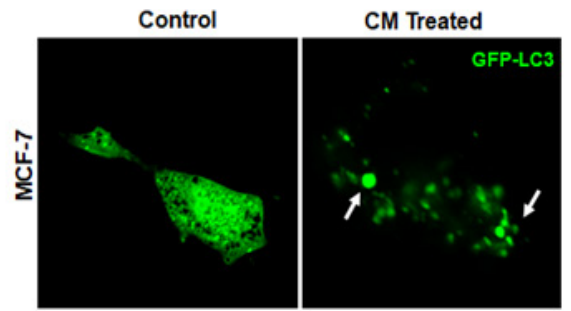

Figure 5. Camel Milk Induces Autophagy. (a, b): Light microscopy images showing comparative morphological changes in HCT 116 and MCF-7 cells untreated or treated with camel milk for $24 \mathrm{~h}$. The black arrows indicate the presence of vesicles. Scale bar: $15 \mu \mathrm{m}$. (c, d): Confocal microscopy images showing the localization of GFP-LC3 puncta (white arrows) in HCT 116 and MCF-7 cells treated with camel milk in compared to the diffused fluorescence in the untreated cells. Cells were transiently transfected with pEGFP-LC3 plasmid for $24 \mathrm{~h}$ and then the GFP-LC3 positive cells were treated with or without $100 \mu \mathrm{L} / \mathrm{mL}$ camel milk for additional $24 \mathrm{~h}$. Fluorescence images were captured at 60x magnification, scale bar: $20 \mu \mathrm{m}$.

Camel milk treatment stimulated autophagosome formation in cancer cells

To characterize the autophagic activity in camel milk treated cells, green fluorescence GFP-LC3 transient transfection technique was used to detect the formation of autophagosomes. In control (untreated) HCT 116 and
MCF-7 cells, a diffused fluorescence signal of GFP-LC3 was observed (Figure 5c, 5d) while, in both HCT 116 and MCF-7 cells cultured in the presence of camel milk, the GFP-LC3 puncta accumulated indicating the formation of autophagosomes (Figure 5c, 5d).

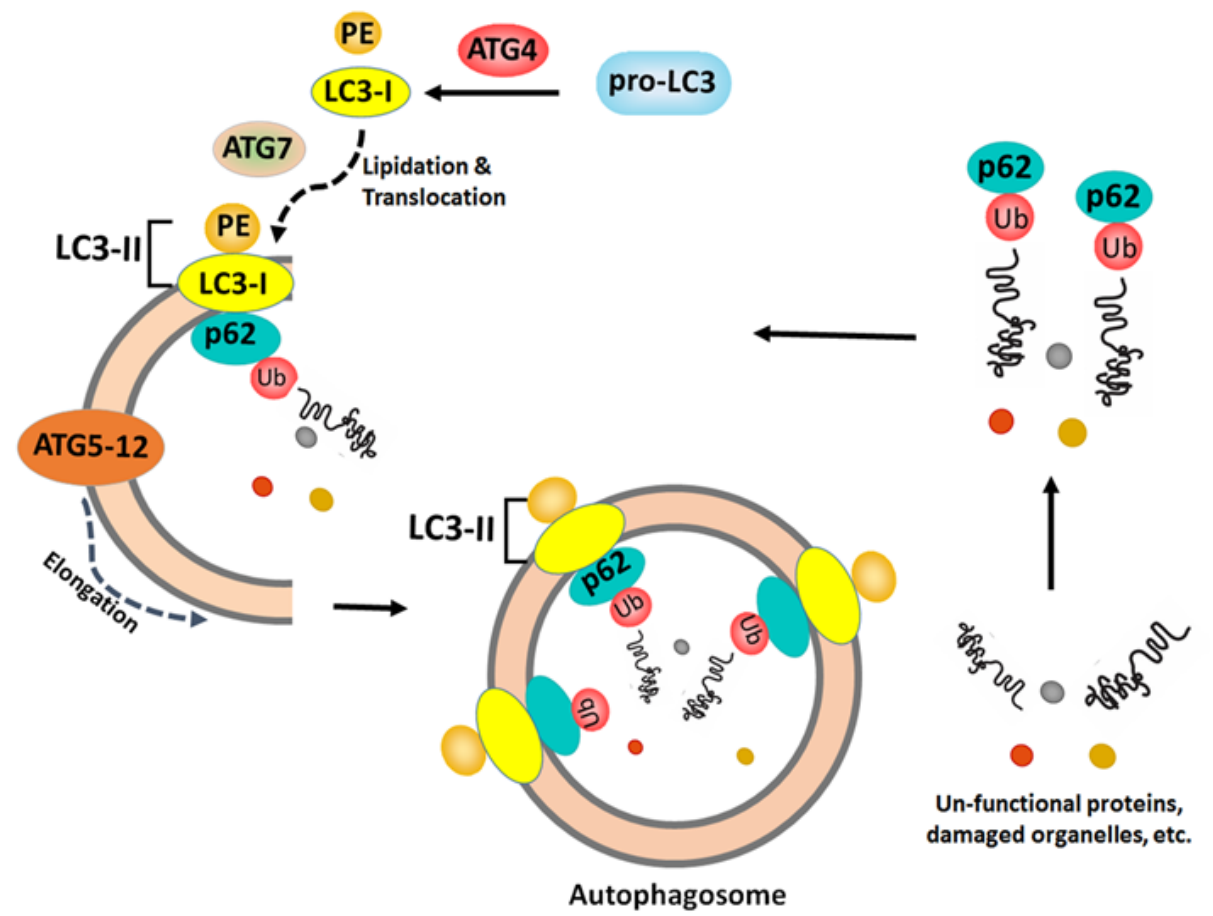

Figure 6. Schematic Representation of Autophagic Flux and Formation of Autophagosomes Emphasising the Role of Various Proteins Involved. Microtubule-associated protein 1 light chain 3 (LC3) precursors are processed to form LC3-I is lipidated by phosphatidyl ethanolamine (PE) forms the active LC3-II which is then localized onto the double membrane vesicles that forms the nascent autophagosomes. The autophagy proteins such as Atg $5 \operatorname{and} A \operatorname{tg} 12$ forms a complex (Atg5-12), then gets directed onto to the double membrane vesicles, further mediates elongation process leading to the autophagosome formation. The protein p62 (sequestosome 1) co-localizes with the ubiquitinated proteins (fated to be degraded) gets sequestered into the double membrane vesicles, subsequently engulfs into the autophagosomes destined for degradation. 


\section{Discussion}

Camel milk has been reported to possess anti-cancer activity as proved by a few of the in vitro and in vivo studies (Korashy et al., 2012a; Korashy et al., 2012b; Habib et al., 2013; Alhaider et al., 2014; Hasson et al., 2015). Lyophilized camel milk has been shown to inhibit growth and proliferation of many cancer cell types such as human breast cancer BT-474, laryngeal HE-p2 (Hasson et al., 2015), human hepatoma HepG2 (Korashy et al., 2012b) and murine hepatoma Hepa 1c1c7 cells (Korashy et al., 2012a). In addition camel milk protein 'lactoferrin' has been shown to inhibit the proliferation of human colorectal cancer HCT 116 cells by exerting antioxidant and DNA damage activities (Habib et al., 2013). The present study, was aimed to evaluate the growth inhibitory effects of camel milk (commercial) in human colorectal HCT 116 and breast MCF-7 cells and elucidate the underlying mechanism.

Apoptosis and autophagy represent two distinct cellular processes that leads to cell death. Apoptosis (type I programmed cell death) is a cell suicidal program that occurs in response to various homeostatic as well as pathological states by which the cell orchestrates to its death. This cell death process is characterized by morphological changes such as membrane blebbing, formation of apoptotic bodies and chromatin condensation, DNA fragmentation as well as cleavage of poly (ADP-ribose) polymerase (PARP) protein (Berger and Petzold, 1985). PARP cleavage by the proteolytic action of suicidal proteases resulting in signature fragments (89 $\mathrm{kD}$ and $24 \mathrm{kD}$ ) forms one of the hallmarks of apoptosis. In our study, no PARP cleavage was detected (Figure 4a, e) in both the cell lines treated with camel milk. Though PARP cleavage forms a prominent marker of apoptosis, this proteolytic cleavage alone cannot be assessed for the induction of apoptosis. B-cell lymphoma 2 (Bcl-2) is a known anti-apoptotic protein that regulates the process of apoptosis. Expression of Bcl-2 blocks the cell death process of apoptosis and certain types of cancer cells has been found to rely on Bcl-2 for their survival (Brunelle and Letai, 2009). In our study, the protein extracts obtained from both the cell lines treated with camel milk, no modulated expression of Bcl-2 protein was observed in the treated compared to untreated (Figure $4 \mathrm{a}, \mathrm{e}$ ). Taken together, these data suggest that the cytotoxicity effects exerted by the commercially available camel milk on HCT 116 and MCF-7 cells were not through the mechanism of apoptosis as per our experimental conditions. Hence, we looked for the markers of autophagy, the type II programmed cell death.

Autophagy also known as self-eating/auto-digestion is a mechanism of the cells by which it dissipates the non-functional or long-lived proteins and damaged organelles within the cells (Thorburn, 2008). Autophagy is normally induced in cells in response to stimuli such as metabolic stress, but it has been observed that many of the anti-cancer agents used for therapeutic intervention also raise the autophagic flux in cells (Mathew et al., 2007). Autophagy is a highly regulated cellular process with many of the evolutionarily conserved proteins involved in the formation of autophagic vesicles called autophagosomes. A schematic representation of the induction of autophagy leading to autophagosome formation emphasizing the role of various proteins involved is depicted in Figure 6.

The HCT 116 and MCF-7 cells treated with the commercial camel milk were observed to have significant morphological changes characterized mainly by lose of cell membrane integrity along with extensive vacuolization (Figure 5a, b); atypical characteristics of autophagy. Microtubule-associated protein 1 light chain 3 (LC3) is a known marker of autophagy having isoforms, of which: LC3-I gets lipidated by phosphatidyl ethanolamine (PE) forms the active isomer: LC3-II, which gets translocated onto the double membrane vesicles that forms the nascent autophagosomes. Thus, the ratio of LC3-II/LC3-I represents the autophagic flux and the LC3-II protein forms the autophagosome marker, being localized on the surface of autophagosomes.

Upon initiation of autophagy, portions of the cytoplasm are sequestered into double membrane vesicles wherein, the protein p62 (sequestosome 1) co-localizes with the ubiquitinated proteins (that are destined to be degraded) also get sequestered into the double membrane vesicles and gets engulfed into the matured autophagosomes for degradation. The autophagy proteins: Atg5 and Atg12 forms a complex (Atg5-12), that gets directed onto to the double membrane vesicles and mediates elongation process leading to the autophagosome formation.

Our data demonstrated a dose-dependent increase in the LC3-I to LC3-II conversion in HCT 116 and MCF-7 cells treated with camel milk (Figure $4 \mathrm{~b}, \mathrm{f}$ ). This represents the autophagic flux and the formation of autophagosomes. The dose-dependent decrease in the expression of p62 (sequestosome 1) protein in both the cell lines treated with camel milk, evidenced the sequestration process- an initial step in the formation of double membrane vesicles. Similarly, the dose-dependent decrease in expression of Atg5-12 protein in both the cell lines with camel milk indicated the formation of autophagosomes, as this protein is involved only in the elongation process during the autophagosome formation. In addition, the cells transiently expressing GFP-LC3 when treated with camel milk, resulted in the localization of green fluorescent GFP-LC3 puncta as observed under the confocal microscope implied the formation of autophagosomes with LC3 protein, a hallmark of autophagy. In conclusion, the camel milk used in the current study exerts cytotoxicity effects on human colorectal HCT 116 and breast MCF-7 cancer cells by the induction of autophagy.

Camel milk has already been reported to possess medicinal as well as therapeutic properties due to its components such as vitamins E and C (Farah et al., 1992), lysozymes, lactoferrins, lactoperoxidase (el Agamy et al., 1992) and immunoglobulins (Konuspayeva et al., 2007). Among the afore-mentioned components lactoferrin, an iron-binding glycoprotein has been reported to exert anti-cancer activity in murine melanoma (B16-F10) cells through the inhibition of cytochrome P450 1A1 activation (Roseanu et al., 2010). Camel milk's lactoferrin has also been shown to inhibit the growth of colon cancer HCT 116 cells and exert antioxidant as well as DNA damage 
inhibitory activities (Habib et al., 2013). In accordance with these previous studies, we anticipate that it could be the component lactoferrin in the camel milk that exerts the anticancer effects on colon and breast cancer cells tested in this study. Further research is this direction is highly under consideration and will be pursued to identify the active component(s) of the camel milk that can selectively kill cancer cells. Though the potential component of the camel milk capable of inducing autophagy in the cancer cells was not particularly investigated in the current study, our data clearly has shown the anticancer effect exerted by the whole camel milk which is of commercial use. The camel milk used in the current study being a commercial product, it is safe for public use and in case of cancer patients, consuming camel milk will certainly not bring in any side effects but on the other hand could be of some positive effects. The current study can serve as a base and does urge for more in vitro as well as in vivo studies which would help in extending it to some prospective clinical trials.

\section{Funding Statement}

This study was supported by the Medical Research Center (grant: MRC\#16283/16), Hamad Medical Corporation, Doha, State of Qatar.

\section{Conflict of interest}

The authors do not have any conflict of interest to declare.

\section{Acknowledgements}

The authors are grateful to Prof. Serhiy Souchelnytskyi, College of Medicine, Qatar University, Dr. Anna Halama, Weill Cornell Medicine-Qatar and Dr. Jeorge Buddenkotte, Dept. of Dermatology and Venereology, Translational Research Institute, Hamad Medical Corporation for their valuable suggestions and input.

\section{References}

Agrawal RP, Dogra R, Mohta N, et al (2009). Beneficial effect of camel milk in diabetic nephropathy. Acta Biomedica, 80, 131-4.

Al-Kuraya K, Schraml P, Sheikh S, et al (2005). Predominance of high-grade pathway in breast cancer development of Middle East women. Mod Pathol, 18, 891-7.

Al Tamimi DM, Shawarby MA, Ahmed A, et al (2010). Protein expression profile and prevalence pattern of the molecular classes of breast cancer--a Saudi population based study. BMC Cancer, 10, 223.

Alebie G, Yohannes S, Worku A (2017). Therapeutic applications of camel's milk and urine against cancer: current development efforts and future perspectives. J Cancer Sci Ther, 9, 468-78.

Alhaider AA, Abdel Gader AG, Almeshaal N, et al (2014). Camel milk inhibits inflammatory angiogenesis via downregulation of proangiogenic and proinflammatory cytokines in mice. Acta Pathologica Microbiologica Et Immunonologica Scandinavica, 122, 599-607.

Arafa MA, Farhat K (2015). Colorectal cancer in the Arab world-screening practices and future prospects. Asian Pac J Cancer Prev, 16, 7425-30.

Bazarbashi S, Al Eid H, Minguet J (2017). Cancer incidence in
Saudi Arabia: 2012 data from the Saudi Cancer Registry. Asian Pac J Cancer Prev, 18, 2437-44.

Bener A, Ayub H, Kakil R, et al (2008). Patterns of cancer incidence among the population of Qatar: a worldwide comparative study. Asian Pac J Cancer Prev, 9, 19-24.

Bener A, Moore MA, Ali R, et al (2010). Impacts of family history and lifestyle habits on colorectal cancer risk: a case-control study in Qatar. Asian Pac J Cancer Prev, 11, 963-8.

Bener A, Zirie MA, Kim EJ, et al (2012). Measuring burden of diseases in a rapidly developing economy: state of Qatar. Glob J Health Sci, 5, 134-44.

Berger NA, Petzold SJ (1985). Identification of minimal size requirements of DNA for activation of poly(ADP-ribose) polymerase. Biochem, 24, 4352-5.

Brunelle JK, Letai A (2009). Control of mitochondrial apoptosis by the Bcl-2 family. $J$ Cell Sci, 122, 437-41.

D'Amours D, Sallmann FR, Dixit VM, et al (2001). Gain-of-function of poly(ADP-ribose) polymerase-1 upon cleavage by apoptotic proteases: implications for apoptosis. J Cell Sci, 114, 3771-8.

el Agamy EI, Ruppanner R, Ismail A, et al (1992). Antibacterial and antiviral activity of camel milk protective proteins. $J$ Dairy Res, 59, 169-75.

Farah Z, Rettenmaier R, Atkins D (1992). Vitamin content of camel milk. Int J Vitam Nutr Res, 62, 30-3.

Habib HM, Ibrahim WH, Schneider-Stock R, et al (2013). Camel milk lactoferrin reduces the proliferation of colorectal cancer cells and exerts antioxidant and DNA damage inhibitory activities. Food Chem, 141, 148-52.

Haddadin MS, Gammoh SI, Robinson RK (2008). Seasonal variations in the chemical composition of camel milk in Jordan. J Dairy Res, 75, 8-12.

Harrison RA, Oliver J, Hasson SS, et al (2003). Novel sequences encoding venom $\mathrm{C}$-type lectins are conserved in phylogenetically and geographically distinct Echis and Bitis viper species. Gene, 315, 95-102.

Hasson SS, Al-Busaidi JZ, Al-Qarni ZA, et al (2015). In vitro apoptosis triggering in the BT-474 human breast cancer cell line by lyophilised camel's milk. Asian Pac J Cancer Prev, 16, 6651-61.

Hussain AR, Ahmed M, Ahmed S, et al (2011). Thymoquinone suppresses growth and induces apoptosis via generation of reactive oxygen species in primary effusion lymphoma. Free Radic Biol Med, 50, 978-87.

Kittaneh M, Montero AJ, Gluck S (2013). Molecular profiling for breast cancer: a comprehensive review. Biomark Cancer, 5, 61-70.

Kommanee J, Preecharram S, Daduang S, et al (2012). Antibacterial activity of plasma from crocodile (Crocodylus siamensis) against pathogenic bacteria. Ann Clin Microbiol Antimicrob, 11, 22.

Kontou N, Psaltopoulou T, Panagiotakos D, et al (2011). The mediterranean diet in cancer prevention: a review. $J$ Med Food, 14, 1065-78.

Konuspayeva G, Faye B, Loiseau G, et al (2007). Lactoferrin and immunoglobulin contents in camel's milk (Camelus bactrianus, Camelus dromedarius, and Hybrids) from Kazakhstan. J Dairy Sci, 90, 38-46.

Korashy HM, El Gendy MA, Alhaider AA, et al (2012a). Camel milk modulates the expression of aryl hydrocarbon receptor-regulated genes, Cyp1a1, Nqo1, and Gsta1, in murine hepatoma Hepa 1c1c7 cells. J Biomed Biotechnol, 2012, 782642.

Korashy HM, Maayah ZH, Abd-Allah AR, et al (2012b). Camel milk triggers apoptotic signaling pathways in human hepatoma HepG2 and breast cancer MCF7 cell lines through 
transcriptional mechanism. J Biomed Biotechnol, 2012, 593195.

Korish AA, Arafah MM (2013). Camel milk ameliorates steatohepatitis, insulin resistance and lipid peroxidation in experimental non-alcoholic fatty liver disease. $B M C$ Complement Altern Med, 13, 264.

Liang CC, Park AY, Guan JL (2007). In vitro scratch assay: a convenient and inexpensive method for analysis of cell migration in vitro. Nat Protoc, 2, 329-33.

Martinou JC, Youle RJ (2011). Mitochondria in apoptosis: Bcl-2 family members and mitochondrial dynamics. Dev Cell, 21, 92-101.

Mathew R, Karantza-Wadsworth V, White E (2007). Role of autophagy in cancer. Nat Rev Cancer, 7, 961-7.

Mosmann T (1983). Rapid colorimetric assay for cellular growth and survival: application to proliferation and cytotoxicity assays. J Immunol Methods, 65, 55-63.

Mothana RA, Al-Musayeib NM, Matheeussen A, et al (2012). Assessment of the in vitro antiprotozoal and cytotoxic potential of 20 selected medicinal plants from the island of Soqotra. Molecules, 17, 14349-60.

Rasul KI, Awidi AS, Mubarak AA, et al (2001). Study of colorectal cancer in Qatar. Saudi Med J, 22, 705-7.

Roseanu A, Florian PE, Moisei M, et al (2010). Liposomalization of lactoferrin enhanced its anti-tumoral effects on melanoma cells. Biometals, 23, 485-92.

Rossi A, Caracciolo V, Russo G, et al (2008). Medulloblastoma: from molecular pathology to therapy. Clin Cancer Res, 14, 971-6.

Shamsia SM (2009). Nutritional and therapeutic properties of camel and human milks. Int J Genet Mol Biol, 1, 52-8.

Tanida I, Ueno T, Kominami E (2004). LC3 conjugation system in mammalian autophagy. Int $J$ Biochem Cell Biol, 36, 2503-18.

Thorburn A (2008). Apoptosis and autophagy: regulatory connections between two supposedly different processes. Apoptosis, 13, 1-9.

Wernery U (2006). Camel milk, the white gold of the desert. J Camel Pract Res, 13, 15-26.

Yagil R (2013). Camel milk and its unique anti-diarrheal properties. Isr Med Assoc J, 15, 35-6.

\section{(ब) $(\mathbb{8}$}

This work is licensed under a Creative Commons AttributionNon Commercial 4.0 International License. 